\title{
Biofilm Localization in the Vertical Wall of Shaking 96-Well Plates
}

\author{
Luciana C. Gomes, Joana M. R. Moreira, Manuel Simões, \\ Luís F. Melo, and Filipe J. Mergulhão
}

LEPABE, Department of Chemical Engineering, Faculty of Engineering, University of Porto, Rua Dr. Roberto Frias, 4200-465 Porto, Portugal

Correspondence should be addressed to Filipe J. Mergulhão; filipem@fe.up.pt

Received 20 November 2013; Accepted 19 December 2013; Published 13 April 2014

Academic Editors: M. Rodrigues and A. Sellam

Copyright (C) 2014 Luciana C. Gomes et al. This is an open access article distributed under the Creative Commons Attribution License, which permits unrestricted use, distribution, and reproduction in any medium, provided the original work is properly cited.

Microtiter plates with 96 wells are being increasingly used for biofilm studies due to their high throughput, low cost, easy handling, and easy application of several analytical methods to evaluate different biofilm parameters. These methods provide bulk information about the biofilm formed in each well but lack in detail, namely, regarding the spatial location of the biofilms. This location can be obtained by microscopy observation using optical and electron microscopes, but these techniques have lower throughput and higher cost and are subjected to equipment availability. This work describes a differential crystal violet (CV) staining method that enabled the determination of the spatial location of Escherichia coli biofilms formed in the vertical wall of shaking 96-well plates. It was shown that the biofilms were unevenly distributed on the wall with denser cell accumulation near the air-liquid interface. The results were corroborated by scanning electron microscopy and a correlation was found between biofilm accumulation and the wall shear strain rates determined by computational fluid dynamics. The developed method is quicker and less expensive and has a higher throughput than the existing methods available for spatial location of biofilms in microtiter plates.

\section{Introduction}

Biofilms are defined as structured microbial communities that are attached to a surface and encapsulated within a selfproduced matrix $[1,2]$. They constitute a serious problem for public health because of the increased resistance of biofilmassociated microorganisms to antimicrobial agents and their potential to cause infections in patients with indwelling medical devices $[1,3]$.

Intensive studies on the mechanisms of biofilm formation and resistance have encouraged the development of different in vitro platforms, such as microtiter plates (MTPs), which are one of the most widely used biofilm model systems $[4,5]$. In these systems, biofilms are formed on the bottom and on the wall [6] of the microtiter plate wells (most commonly a 96-well plate) or they are grown on the surface of a coupon placed in the wells of the MTP (most commonly a 6-, 12-, or 24-well plate). The large number of advantages offered by these straightforward and user-friendly systems explain their widespread use (Table 1). In addition, several standard assays are available for the determination of different parameters related to the biofilm in MTPs [7]. They can be categorized into biofilm biomass assays (quantitation of matrix and both living and dead cells), viability assays (determination of viable cells), and matrix quantitation assays (through specific staining of matrix components) (Table 1). Microtiter plates have been intensively used in clinical research for screening of antimicrobial compounds $[8,9]$ and for studying biofilm formation [10,11] and inhibition [12, 13]. The most widely used method for following biofilm formation in MTPs is the crystal violet $(\mathrm{CV})$ staining, derived from the original Christensen et al. [14] method, which only measured biofilm biomass at the bottom of the well. CV is a basic dye that stains both living and dead cells by binding to negatively charged surface molecules and polysaccharides in the extracellular matrix of biofilms [15]. Later, the CV assay was modified to increase its accuracy and to allow for biofilm biomass quantitation in the entire well by the solubilization of the 
TABLE 1: Advantages of MTPs as biofilm reactors and standard methods for quantitation of biofilm parameters in MTPs.

\begin{tabular}{lclc}
\hline Advantages & References & Quantitation assays & References \\
\hline $\begin{array}{l}\text { High throughput } \\
\text { Small volumes of }\end{array}$ & {$[4,40]$} & $\begin{array}{l}\text { Biofilm biomass } \\
\text { reagents }\end{array}$ & {$[1,16]$} \\
Automation & {$[42,43]$} & $\begin{array}{l}\text { Microbial } \\
\text { physiological activity }\end{array}$ & $\begin{array}{l}\text { Microbial cells in the } \\
\text { biofilm }\end{array}$ \\
Multiplexing & {$[4]$} & Biofilm matrix & {$[7,41]$} \\
\hline
\end{tabular}

dye $[16,17]$. This method can therefore be considered a bulk method which provides information about the total amount of biofilms produced without revealing any information about biofilm localization. It has been shown that the biofilm distribution in the wall of a 96-well MTP may not be uniform when dynamic conditions are used (when the MTP is shaken with an orbital motion) [6]. This biofilm heterogeneity can be analyzed, for instance, by microscopy either using standard optical microscopy [18], confocal laser scanning microscopy (CLSM) [19], or scanning electron microscopy (SEM) [20]. The relative advantages and limitations of these two later techniques are presented in Table 2. It is interesting to point out that, for the most part, these microscopy analyses are made at the bottom of the well, disregarding the biofilm that is formed on the vertical wall. Both techniques enable spatial localization of the biofilms, but are inherently low throughput techniques, with a high cost and are subjected to equipment availability. The aim of this work was to develop a low cost and high throughput method that would enable the quantitation of the total amount of biofilm produced inside a well but providing the same information about the spatial location of the formed biofilm. A differential CV staining method was here developed by combining the high throughput features of the usual CV staining but enabling spatial localization of the biofilm without the use of expensive equipment.

\section{Materials and Methods}

2.1. Computational Fluid Dynamic (CFD) Simulations. Numerical simulations were made in Ansys Fluent CFD package (version 13.0) as previously described [6]. A cylindrical well (diameter of $6.6 \mathrm{~mm}$ and height of $11.7 \mathrm{~mm}$ ) was built in Design Modeller 13.0 and discretized into a grid of 18,876 hexahedral cells by Meshing 13.0. Simulation was made for a shaking diameter of $50 \mathrm{~mm}$ and frequency of $150 \mathrm{rpm}$. The location of the interface was determined by Ansys Fluent, as well as the magnitude of the shear strain rate. The time averaged shear strain rate was obtained by averaging the steady state shear strain rate of the liquid side during a complete orbit.

2.2. Biofilm Formation in 96-Well Microtiter Plates. Escherichia coli JM109(DE3) from Promega (USA) was used to form biofilms in 96-well microtiter plates because this strain has shown a good biofilm forming ability in both turbulent [21] and laminar [6] flow conditions. Its
Its genotype is endA1, $\operatorname{rec} \mathrm{A} 1, \operatorname{gyr} \mathrm{A} 96$, thi, hsdR17 $\left(\mathrm{r}_{\mathrm{k}}{ }^{-}\right.$, $\left.\mathrm{m}_{\mathrm{k}}^{+}\right)$, relA1, supE44, $\lambda^{-}, \Delta($ lac-proAB $),\left(\mathrm{F}^{\prime}\right.$, traD36, proAB, lac $\left.\mathrm{I}^{\mathrm{q}} \mathrm{Z} \Delta \mathrm{M} 15\right)$, and $\lambda(\mathrm{DE} 3)$. Cells from an overnight culture were prepared as previously described [6] and biofilms were produced by pipetting $20 \mu \mathrm{L}$ of these cells into six wells of sterile 96-well flat-bottomed microtiter plates (Orange Scientific, USA) filled with $180 \mu \mathrm{L}$ of nutrient media. The media used was identical to the one described in [22], except for glucose. A glucose concentration of $1 \mathrm{gL}^{-1}$ was used in this work since it has been demonstrated that this concentration originated the maximum biofilm amount at $24 \mathrm{~h}$ in different shaking conditions [6]. Microtiter plates were placed for $24 \mathrm{~h}$ at $30^{\circ} \mathrm{C}$ in an orbital shaking incubator with $50 \mathrm{~mm}$ of diameter at $150 \mathrm{rpm}$ (CERTOMAT BS-1, Sartorius AG, Germany).

2.3. Biofilm Quantitation by Crystal Violet (CV) Staining. The amount of biofilm formed was measured using the CV dye in a differential form; this means that the well has been divided into four different sections (Figure $1(\mathrm{~d})$ ) and the corresponding vertical wall section was stained sequentially up to a maximum volume of $200 \mu \mathrm{L}$. Biofilm quantitation on the bottom of the well was performed by using $25 \mu \mathrm{L}$ of $\mathrm{CV}$ for staining (as detailed below). Section 1 corresponded to a volume between 25 and $50 \mu \mathrm{L}$ (and a height of $0.77 \mathrm{~mm}$ ). Section 2 corresponded to a volume between 50 and $100 \mu \mathrm{L}$, section 3 corresponded to a volume between 100 and $150 \mu \mathrm{L}$ and section 4 corresponded to a volume between 150 and $200 \mu \mathrm{L}$. Sections 2, 3, and 4 had an equivalent height of $1.54 \mathrm{~mm}$.

Prior to CV staining, the contents of the microtiter plates were discarded and the wells were washed with $200 \mu \mathrm{L}$ of sterile water to remove non-adherent bacteria [16]. Then, the biofilms were fixed with $250 \mu \mathrm{L}$ of $96 \%$ ethanol [23]. The first section of the well to be quantified was the bottom (not represented in Figure $1(\mathrm{~d})$ ), which corresponds to a volume of $25 \mu \mathrm{L}$ and a height of $0.77 \mathrm{~mm}$. The cells adhered to this region were stained for $5 \mathrm{~min}$ with the correspondent volume of $1 \%(\mathrm{v} / \mathrm{v})$ crystal violet (Merck, Germany) and the dye bound to this specific region was solubilized with $200 \mu \mathrm{L}$ of $33 \%(\mathrm{v} / \mathrm{v})$ acetic acid (VWR, Portugal). The absorbance was measured at $570 \mathrm{~nm}$ using a microtiter plate reader (SpectraMax M2E, Molecular Devices, UK). The biofilms formed in the successive sections of the well (sections 1 to 4 of Figure 1(d)) were quantified using the described procedure, specifically using the CV volume equivalent to the maximum level of each section (section $1-50 \mu \mathrm{L}$; section $2-100 \mu \mathrm{L}$; section $3-150 \mu \mathrm{L}$; section $4-200 \mu \mathrm{L}$ ). The absorbance corresponding to each of the defined sections and presented on Figure $1(\mathrm{~d})$ was calculated by subtracting the absorbances from the previous sections and considering the dilution factor. To quantify the biofilm formed in each of the well sections, six replica wells were used per experiment and three independent experiments were performed.

2.4. Scanning Electron Microscopy (SEM). Microtiter plate wells containing $24 \mathrm{~h}$ old biofilms were imaged by SEM as previously described [24]. Briefly, biofilms were fixed in 3\% 
TABLE 2: Advantages and limitations of scanning electron microscopy (SEM) and confocal laser scanning microscopy (CLSM) on biofilm analysis.

\begin{tabular}{lll}
\hline Technique & Advantages & Limitations \\
\hline $\begin{array}{l}\text { Scanning electron } \\
\text { microscopy }\end{array}$ & $\begin{array}{l}\text { High resolution } \\
\text { Wide range of magnifications } \\
\text { Good comparative information } \\
\text { Ability to image complex shapes }\end{array}$ & $\begin{array}{l}\text { Not real time } \\
\text { Requires additional sample preparation } \\
\text { Limited quantification }\end{array}$ \\
\hline $\begin{array}{l}\text { Confocal laser scanning } \\
\text { microscopy }\end{array}$ & $\begin{array}{l}\text { Living, fully hydrated samples } \\
\text { Non-invasive } \\
\text { Quantitative evaluation } \\
\text { Reflection and fluorescence mode }\end{array}$ & $\begin{array}{l}\text { Low resolution } \\
\text { Narrow range of magnifications } \\
\text { Not applicable to thick biofilms }\end{array}$ \\
\hline
\end{tabular}
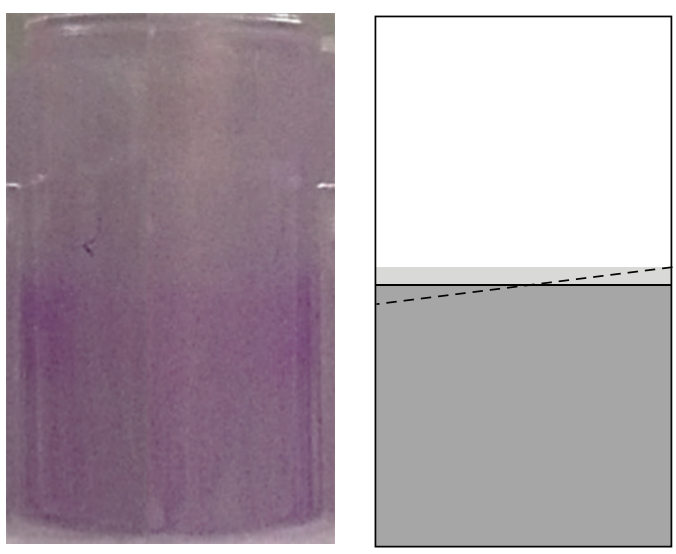

- Increased wetted area

- Static fill volume

(b)

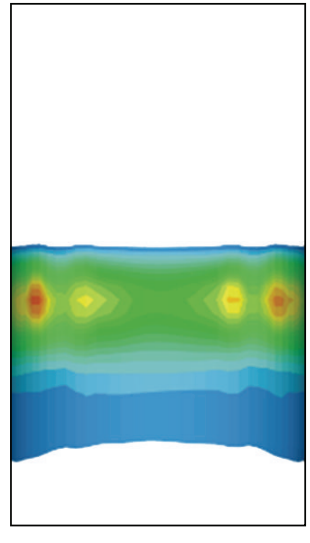

$20 \quad 40 \quad 6080100120140160180$ Strain rate $\left(\mathrm{s}^{-1}\right)$

(d)

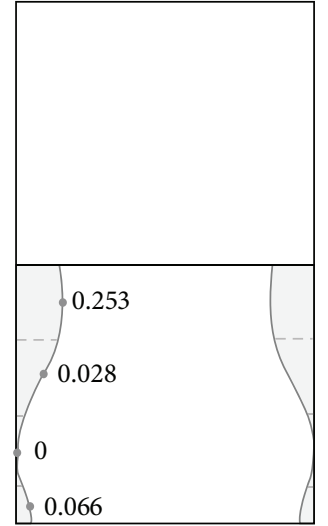

Absorbance $(570 \mathrm{~nm})$

(c)

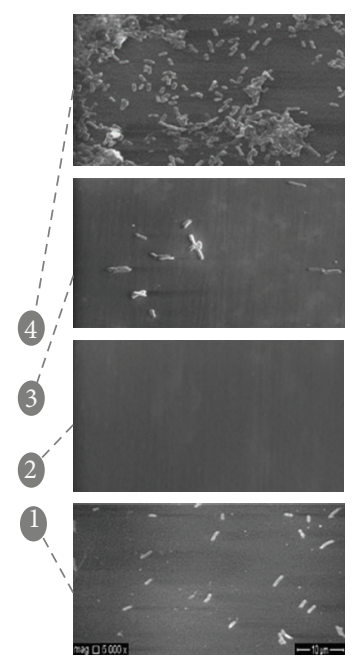

(e)

FIGURE 1: Biofilm localization in shaking 96-well microtiter plates placed in a $50 \mathrm{~mm}$ incubator at $150 \mathrm{rpm}$. (a) Photograph of a well stained with crystal violet; (b) schematic representation of a well where the dark grey area corresponds to the wetted area without shaking, the light grey area represents the area increase upon shaking, and the dotted line depicts the inclination of the air-liquid interface; (c) time averaged shear strain rates (values below $20 \mathrm{~s}^{-1}$ are not represented); (d) illustration of the biofilm distribution on the vertical wall assayed by the differential CV staining; (e) representative scanning electron micrographs of the wall sections defined in image (d); (5000x magnification bar $=10 \mu \mathrm{m})$.

(w/w) glutaraldehyde in cacodylate buffer, dehydrated with ethanol and hexamethyldisilazane (HMDS), and sputtercoated with a palladium-gold thin film. The different sections along the vertical wall of three independent wells were observed with a SEM/EDS system (FEI Quanta 400FEG ESEM/EDAX Genesis X4 M, FEI Company, USA).

\section{Results and Discussion}

The effect of orbital shaking on biofilm formation in 96well microtiter plates was firstly assessed by the conventional procedure of crystal violet staining $[6,16]$. Through direct observation of the stained wells (prior to solubilization of the dye), it was possible to observe that biofilms were mainly formed on the wall and not on the bottom of the well. Moreover, since the amount of produced biofilms is proportional to the amount of $\mathrm{CV}$ adsorbed, it seemed that the biofilm was unevenly distributed in the cylindrical wall and higher amounts were formed closer to the air-liquid interface (Figure 1(a)).

It is widely known that hydrodynamics affects biofilm formation [25-27] as a result of the shear forces that can modulate cell adhesion to a given surface [28-31]. Even though microtiter plates are broadly accepted as biofilm formation reactors by the scientific community, there is still a lack of information on the impact of hydrodynamics on biofilm formation in this system. In this work, the flow inside the wells was simulated using computational fluid dynamics (Figures 1(b) and 1(c)) in order to find out if the hydrodynamic conditions were related to the uneven biofilm distribution that was visible to the naked eye after $\mathrm{CV}$ staining (Figure 1(a)). Figure 1(b) represents a scale model of a microwell with the wetted area without orbital motion, the area increase upon shaking, and the inclination of the air-liquid interface. For the shaking conditions chosen for this work ( $50 \mathrm{~mm}$ of orbital diameter and $150 \mathrm{rpm}$ ), an area gain of $8.5 \%$ and a maximum angle of $7.8^{\circ}$ were obtained. 
Similar to what was observed in the photograph of the stained well (Figure 1(a)), the shear strain rate distribution was not uniform along the wall, being much higher in the liquid side near the interface (Figure $1(\mathrm{c})$ ). In this region, CFD simulations revealed some spots, corresponding to a maximum shear strain rate of $180 \mathrm{~s}^{-1}$, which are related to regions of unstable vortices [6].

Observing the results of the differential CV staining (Figure 1(d)), the amount of biofilm detected along the different sections of the wall was not constant. The highest value of absorbance (corresponding to the highest amount of biofilm biomass) was measured in the region located immediately below the liquid level (section 4). In the intermediate sections of the well, the absorbance values were about 10 times lower than near the interface (section 3 ) or almost zero (section 2), increasing slightly in the section closer to the bottom of the well (section 1).

In order to validate the results obtained by the differential $\mathrm{CV}$ staining, SEM analysis was performed on the vertical wall of the wells. Figure 1(e) shows scanning electron micrographs representative of the four sections defined in the application of the differential CV staining (Figure $1(\mathrm{~d})$ ). SEM analysis showed that $E$. coli adhesion varied across the wall and that higher attachment occurred closer to the air-liquid interface (section 4) compared to the intermediate (sections 2 and 3) and near bottom (section 1) regions of the well. Biofilms consisting of bacterial aggregates were observed near the interface, while in the lower regions of the well there were only few cells randomly distributed on the surface (Figure 1(e)).

Most likely the spatial location of the biofilms (assayed by differential staining and SEM analysis) is conditioned by the non-homogeneous distribution of shear strain calculated by CFD during shaking. The higher cell density of the biofilms formed closer to the interface is probably due to the higher oxygen and substrate mass transfer from the bulk solution to the biofilm [32], resulting from a more efficient liquid mixing in this region. These results are in agreement with previous studies $[29,33,34]$ showing that higher shear forces promote the formation of denser biofilms.

Both methods used for biofilm analysis in this work (differential CV staining and SEM) enabled a higher detail in analysis of biofilms grown in 96-well microtiter plates, which is not achieved by the spectrophotometric methods commonly used in MTPs (Table 1). Indeed, methods such as the traditional $\mathrm{CV}$ assay provide bulk data from a biofilm and are classified as macroscale methods, whereas SEM is a microscale technique [24]. It is interesting to notice that the differential CV staining presented in this work corresponds to an intermediate scale between the traditional CV assay and SEM analysis. The traditional CV assay quantifies the biofilm formed on the wall and bottom of each well of a microtiter plate, which corresponds to an area of about $146 \mathrm{~mm}^{2}$ (for a 96-well plate), while the method proposed here evaluates wall sections of about 14 and $28 \mathrm{~mm}^{2}$. In comparison, the area covered by a SEM image taken at 5000x magnification was of $2 \times 10^{-3} \mathrm{~mm}^{2}$, and this technique enables detailed analysis of individual cells within the biofilm rather than simply determining their localization. SEM offers higher magnification (ranging from $20 \mathrm{x}$ to approximately $30,000 \mathrm{x}$ ) and resolution (from 50 to $100 \mathrm{~nm}$ ), together with the ability of imaging complex shapes (Table 2). It is also highly recommended for the visualization of cellular morphology, cellto-cell interactions, and matrix components within biofilms [35]. However, one must bear in mind that most laboratories are not equipped with an electron microscope and this technique has a considerably lower throughput than the methods described in Table 1.

Observation of biofilms formed on the bottom of the wells of microtiter plates is very common using optical microscopes at magnifications of 100 to $200 x$, which typically cover areas of $0.3 \mathrm{~mm}^{2}$ [36-39]. These observations have provided some information about the architecture of the biofilms formed on the bottom of the wells (particularly when CLSM is used) but usually disregard the biofilm that forms on the vertical wall. It has been shown that in dynamic conditions the amount of biofilm formed on the vertical wall can be higher than the one formed on the bottom of the well [6], and therefore a method was developed in this work to determine the spatial localization of these biofilms in a high throughput manner, using common laboratory equipment. The area under analysis in each of the four sections defined for the differential staining is equivalent to the area analyzed by optical microscopy using a $15 \mathrm{x}$ magnification. This area could be further reduced (thus increasing the precision of the method) by dividing the well in sections of smaller height.

The novel approach presented in this work demonstrates that the $\mathrm{CV}$ dye can be extremely useful in locating the adherent cells in microtiter plates when used in a differential way. The method is slightly more laborious and slower than the traditional staining procedure, but it requires fewer resources and has higher throughput than other techniques that are used to determine the spatial location of biofilms.

\section{Conflict of Interests}

The authors declare that there is no conflict of interests regarding the publication of this paper.

\section{Acknowledgments}

The authors acknowledge the financial support provided by Operational Programme for Competitiveness Factors (COMPETE), European Fund for Regional DevelopmentFEDER, and the Portuguese Foundation for Science and Technology (FCT), through Projects PTDC/EBB$\mathrm{BIO} / 102863 / 2008$ and PTDC/EBB-BIO/104940/2008. Luciana Gomes acknowledges the receipt of a Ph.D. Grant from FCT (SFRH/BD/80400/2011). João Miranda and José Araújo (Transport Phenomena Research Center, FEUP) are acknowledged for the numerical simulations.

\section{References}

[1] J. W. Costerton, P. S. Stewart, and E. P. Greenberg, "Bacterial biofilms: a common cause of persistent infections," Science, vol. 284, no. 5418, pp. 1318-1322, 1999. 
[2] P. Stoodley, K. Sauer, D. G. Davies, and J. W. Costerton, "Biofilms as complex differentiated communities," Annual Review of Microbiology, vol. 56, pp. 187-209, 2002.

[3] V. Hancock, L. Ferrières, and P. Klemm, "Biofilm formation by asymptomatic and virulent urinary tract infectious Escherichia coli strains," FEMS Microbiology Letters, vol. 267, no. 1, pp. 30-37, 2007.

[4] T. Coenye and H. J. Nelis, "In vitro and in vivo model systems to study microbial biofilm formation," Journal of Microbiological Methods, vol. 83, no. 2, pp. 89-105, 2010.

[5] J. S. Teodósio, M. Simões, L. F. Melo, and F. J. Mergulhão, "Platforms for in vitro biofilm studies," in Biofilms in Bioengineering, M. Simões and F. Mergulhão, Eds., pp. 45-62, Nova Science, New York. NY, USA, 2013.

[6] J. M. R. Moreira, L. C. Gomes, J. D. P. Araújo et al., "The effect of glucose concentration and shaking conditions on Escherichia coli biofilm formation in microtiter plates," Chemical Engineering Science, vol. 94, pp. 192-199, 2013.

[7] E. Peeters, H. J. Nelis, and T. Coenye, "Comparison of multiple methods for quantification of microbial biofilms grown in microtiter plates," Journal of Microbiological Methods, vol. 72, no. 2, pp. 157-165, 2008.

[8] M. Erriu, F. M. G. Pili, E. Tuveri et al., "Oil essential mouthwashes antibacterial activity against Aggregatibacter actinomycetemcomitans: a comparison between antibiofilm and antiplanktonic effects," International Journal of Dentistry, vol. 2013, Article ID 164267, 5 pages, 2013.

[9] D. Minardi, O. Cirioni, R. Ghiselli et al., "Efficacy of tigecycline and rifampin alone and in combination against Enterococcus faecalis biofilm infection in a rat model of ureteral stent," Journal of Surgical Research, vol. 176, no. 1, pp. 1-6, 2012.

[10] C. Sanchez, K. Mende, M. Beckius et al., "Biofilm formation by clinical isolates and the implications in chronic infections," BMC Infectious Diseases, vol. 13, article 47, 2013.

[11] E. Hell, C. Giske, K. Hultenby et al., "Attachment and biofilm forming capabilities of Staphylococcus epidermidis strains isolated from preterm infants," Current Microbiology, vol. 67, no. 6, pp. 712-717, 2013.

[12] M.-H. Lin, F.-R. Chang, M.-Y. Hua, Y.-C. Wu, and S.T. Liu, "Inhibitory effects of 1,2,3,4,6-penta-O-galloyl- $\beta$-Dglucopyranose on biofilm formation by Staphylococcus aureus," Antimicrobial Agents and Chemotherapy, vol. 55, no. 3, pp. 10211027, 2011

[13] C. De La Fuente-Núñez, V. Korolik, M. Bains et al., "Inhibition of bacterial biofilm formation and swarming motility by a small synthetic cationic peptide," Antimicrobial Agents and Chemotherapy, vol. 56, no. 5, pp. 2696-2704, 2012.

[14] G. D. Christensen, W. A. Simpson, and J. J. Younger, "Adherence of coagulase-negative staphylococci to plastic tissue culture plates: a quantitative model for the adherence of staphylococci to medical devices," Journal of Clinical Microbiology, vol. 22, no. 6, pp. 996-1006, 1985.

[15] X. Li, Z. Yan, and J. Xu, "Quantitative variation of biofilms among strains in natural populations of Candida albicans," Microbiology, vol. 149, no. 2, pp. 353-362, 2003.

[16] S. Stepanović, D. Vuković, I. Dakić, B. Savić, and M. ŠvabićVlahović, "A modified microtiter-plate test for quantification of staphylococcal biofilm formation," Journal of Microbiological Methods, vol. 40, no. 2, pp. 175-179, 2000.

[17] L. Crémet, S. Corvec, E. Batard et al., "Comparison of three methods to study biofilm formation by clinical strains of
Escherichia coli," Diagnostic Microbiology and Infectious Disease, vol. 75, no. 3, pp. 252-255, 2013.

[18] L. R. Martinez and A. Casadevall, "Specific antibody can prevent fungal biofilm formation and this effect correlates with protective efficacy," Infection and Immunity, vol. 73, no. 10, pp. 6350-6362, 2005.

[19] A. Bridier, D. Le Coq, F. Dubois-Brissonnet, V. Thomas, S. Aymerich, and R. Briandet, "The spatial architecture of Bacillus subtilis biofilms deciphered using a surface-associated model and in situ imaging," PLoS ONE, vol. 6, no. 1, Article ID e16177, 2011.

[20] V. Kostenko, M. M. Salek, P. Sattari, and R. J. Martinuzzi, "Staphylococcus aureus biofilm formation and tolerance to antibiotics in response to oscillatory shear stresses of physiological levels," FEMS Immunology and Medical Microbiology, vol. 59, no. 3, pp. 421-431, 2010.

[21] J. S. Teodósio, M. Simões, and F. J. Mergulhão, “The influence of nonconjugative Escherichia coli plasmids on biofilm formation and resistance," Journal of Applied Microbiology, vol. 113, no. 2, pp. 373-382, 2012.

[22] J. S. Teodósio, M. Simões, L. F. Melo, and F. J. Mergulhão, "Flow cell hydrodynamics and their effects on E. coli biofilm formation under different nutrient conditions and turbulent flow," Biofouling, vol. 27, no. 1, pp. 1-11, 2011.

[23] S. Shakeri, R. K. Kermanshahi, M. M. Moghaddam, and G. Emtiazi, "Assessment of biofilm cell removal and killing and biocide efficacy using the microtiter plate test," Biofouling, vol. 23, no. 2, pp. 79-86, 2007.

[24] L. Gomes, J. M. R. Moreira, J. M. Miranda et al., "Macroscale versus microscale methods for physiological analysis of biofilms formed in 96-well microtiter plates," Journal of Microbiological Methods, vol. 95, no. 3, pp. 342-349, 2013.

[25] Y. Liu and J.-H. Tay, "The essential role of hydrodynamic shear force in the formation of biofilm and granular sludge," Water Research, vol. 36, no. 7, pp. 1653-1665, 2002.

[26] P. Stoodley, S. Wilson, L. Hall-Stoodley, J. D. Boyle, H. M. Lappin-Scott, and J. W. Costerton, "Growth and detachment of cell clusters from mature mixed-species biofilms," Applied and Environmental Microbiology, vol. 67, no. 12, pp. 5608-5613, 2001.

[27] S. Wäsche, H. Horn, and D. C. Hempel, "Influence of growth conditions on biofilm development and mass transfer at the bulk/biofilm interface," Water Research, vol. 36, no. 19, pp. 47754784, 2002

[28] H. J. Busscher and H. C. van der Mei, "Microbial adhesion in flow displacement systems," Clinical Microbiology Reviews, vol. 19, no. 1, pp. 127-141, 2006.

[29] M. Simões, M. O. Pereira, S. Sillankorva, J. Azeredo, and M. J. Vieira, "The effect of hydrodynamic conditions on the phenotype of Pseudomonas fluorescens biofilms," Biofouling, vol. 23, no. 4, pp. 249-258, 2007.

[30] J. S. Teodósio, F. C. Silva, J. M. R. Moreira et al., "Flow cells as quasi ideal systems for biofouling simulation of industrial piping systems," Biofouling, vol. 29, no. 8, pp. 953-966, 2013.

[31] M. C. M. Van Loosdrecht, D. Eikelboom, A. Gjaltema, A. Mulder, L. Tijhuis, and J. J. Heijnen, "Biofilm structures," Water Science and Technology, vol. 32, no. 8, pp. 35-43, 1995.

[32] J. M. R. Moreira, J. S. Teodósio, F. C. Silva et al., "Influence of flow rate variation on the development of Escherichia coli biofilms," Bioprocess and Biosystems Engineering, vol. 36, no. 11, pp. 1787-1796, 2013. 
[33] W. K. Kwok, C. Picioreanu, S. L. Ong et al., "Influence of biomass production and detachment forces on biofilm structures in a biofilm airlift suspension reactor," Biotechnology and Bioengineering, vol. 58, no. 4, pp. 400-407, 1998.

[34] A. Rochex, J.-J. Godon, N. Bernet, and R. Escudié, "Role of shear stress on composition, diversity and dynamics of biofilm bacterial communities," Water Research, vol. 42, no. 20, pp. 4915-4922, 2008.

[35] A. Bridier, T. Meylheuc, and R. Briandet, "Realistic representation of Bacillus subtilis biofilms architecture using combined microscopy (CLSM, ESEM and FESEM)," Micron, vol. 48, pp. 65-69, 2013.

[36] M. G. White, S. Piccirillo, V. Dusevich, D. J. Law, T. Kapros, and S. M. Honigberg, "Flollp adhesin required for meiotic differentiation in Saccharomyces cerevisiae minicolonies grown on plastic surfaces," FEMS Yeast Research, vol. 11, no. 2, pp. 223232, 2011.

[37] C. L. Quave, M. Estévez-Carmona, C. M. Compadre et al., "Ellagic acid derivatives from Rubus ulmifolius inhibit Staphylococcus aureus biofilm formation and improve response to antibiotics," PLoS ONE, vol. 7, no. 1, Article ID e28737, 2012.

[38] A. Lizcano, T. Chin, K. Sauer, E. I. Tuomanen, and C. J. Orihuela, "Early biofilm formation on microtiter plates is not correlated with the invasive disease potential of Streptococcus pneumoniae," Microbial Pathogenesis, vol. 48, no. 3-4, pp. 124130, 2010.

[39] A. S. Melo, A. L. Colombo, and B. A. Arthington-Skaggs, "Paradoxical growth effect of caspofungin observed on biofilms and planktonic cells of five different Candida species," Antimicrobial Agents and Chemotherapy, vol. 51, no. 9, pp. 3081-3088, 2007.

[40] W. A. Duetz, "Microtiter plates as mini-bioreactors: miniaturization of fermentation methods," Trends in Microbiology, vol. 15, no. 10, pp. 469-475, 2007.

[41] K. Honraet, E. Goetghebeur, and H. J. Nelis, "Comparison of three assays for the quantification of Candida biomass in suspension and CDC reactor grown biofilms," Journal of Microbiological Methods, vol. 63, no. 3, pp. 287-295, 2005.

[42] S. Kumar, C. Wittmann, and E. Heinzle, "Review: minibioreactors," Biotechnology Letters, vol. 26, no. 1, pp. 1-10, 2004.

[43] N. F. Azevedo, S. P. Lopes, C. W. Keevil, M. O. Pereira, and M. J. Vieira, "Time to "go large" on biofilm research: advantages of an omics approach," Biotechnology Letters, vol. 31, no. 4, pp. 477485, 2009.

[44] K. Toté, D. V. Berghe, L. Maes, and P. Cos, "A new colorimetric microtitre model for the detection of Staphylococcus aureus biofilms," Letters in Applied Microbiology, vol. 46, no. 2, pp. 249254, 2008.

[45] T. A. Norton, R. C. Thompson, J. Pope et al., "Using confocal laser scanning microscopy, scanning electron microscopy and phase contrast light microscopy to examine marine biofilms," Aquatic Microbial Ecology, vol. 16, no. 2, pp. 199-204, 1998.

[46] D. O. Serra, A. M. Richter, G. Klauck et al., "Microanatomy at cellular resolution and spatial order of physiological differentiation in a bacterial biofilm," mBio, vol. 4, no. 2, pp. e100103e100113, 2013.

[47] P. S. Stewart, R. Murga, R. Srinivasan, and D. De Beer, "Biofilm structural heterogeneity visualized by three microscopic methods," Water Research, vol. 29, no. 8, pp. 2006-2009, 1995.

[48] S. B. Surman, J. T. Walker, D. T. Goddard et al., "Comparison of microscope techniques for the examination of biofilms," Journal of Microbiological Methods, vol. 25, no. 1, pp. 57-70, 1996.
[49] C. Hannig, M. Follo, E. Hellwig, and A. Al-Ahmad, "Visualization of adherent micro-organisms using different techniques," Journal of Medical Microbiology, vol. 59, no. 1, pp. 1-7, 2010.

[50] A. Bridier, F. Dubois-Brissonnet, A. Boubetra, V. Thomas, and R. Briandet, "The biofilm architecture of sixty opportunistic pathogens deciphered using a high throughput CLSM method," Journal of Microbiological Methods, vol. 82, no. 1, pp. 64-70, 2010.

[51] M. Fedel, P. Caciagli, V. Chistè et al., "Microbial biofilm imaging ESEM vs. HVSEM," Imaging \& Microscopy, vol. 9, no. 2, pp. 4447, 2007.

[52] R. J. Palmer Jr, J. J. Haagensen, T. Neu, and C. Sternberg, "Confocal microscopy of biofilms-spatiotemporal approaches," in Handbook of Biological Confocal Microscopy, J. B. Pawley, Ed., pp. 870-888, Springer, New York, NY, USA, 2006. 

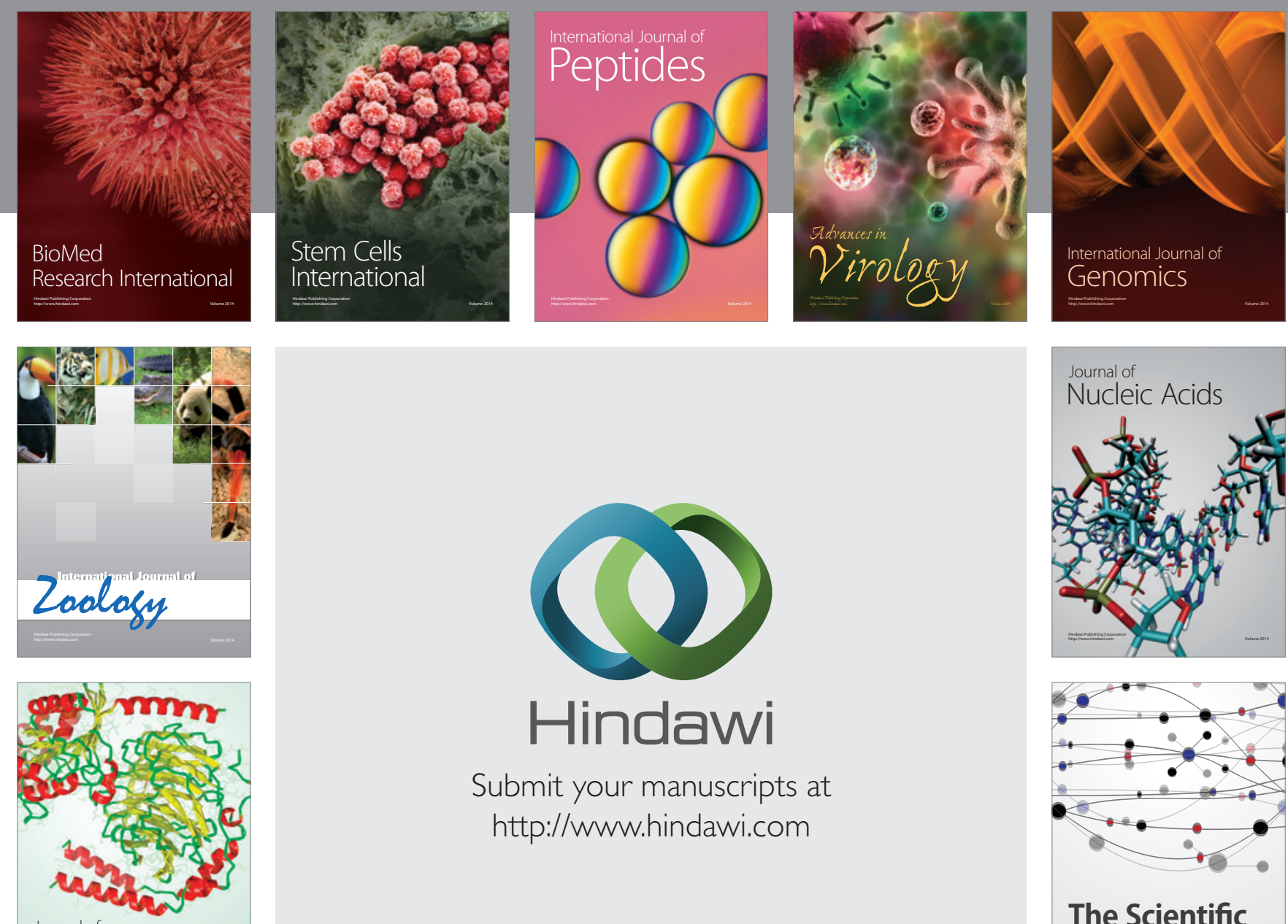

Submit your manuscripts at

http://www.hindawi.com

Journal of
Signal Transduction
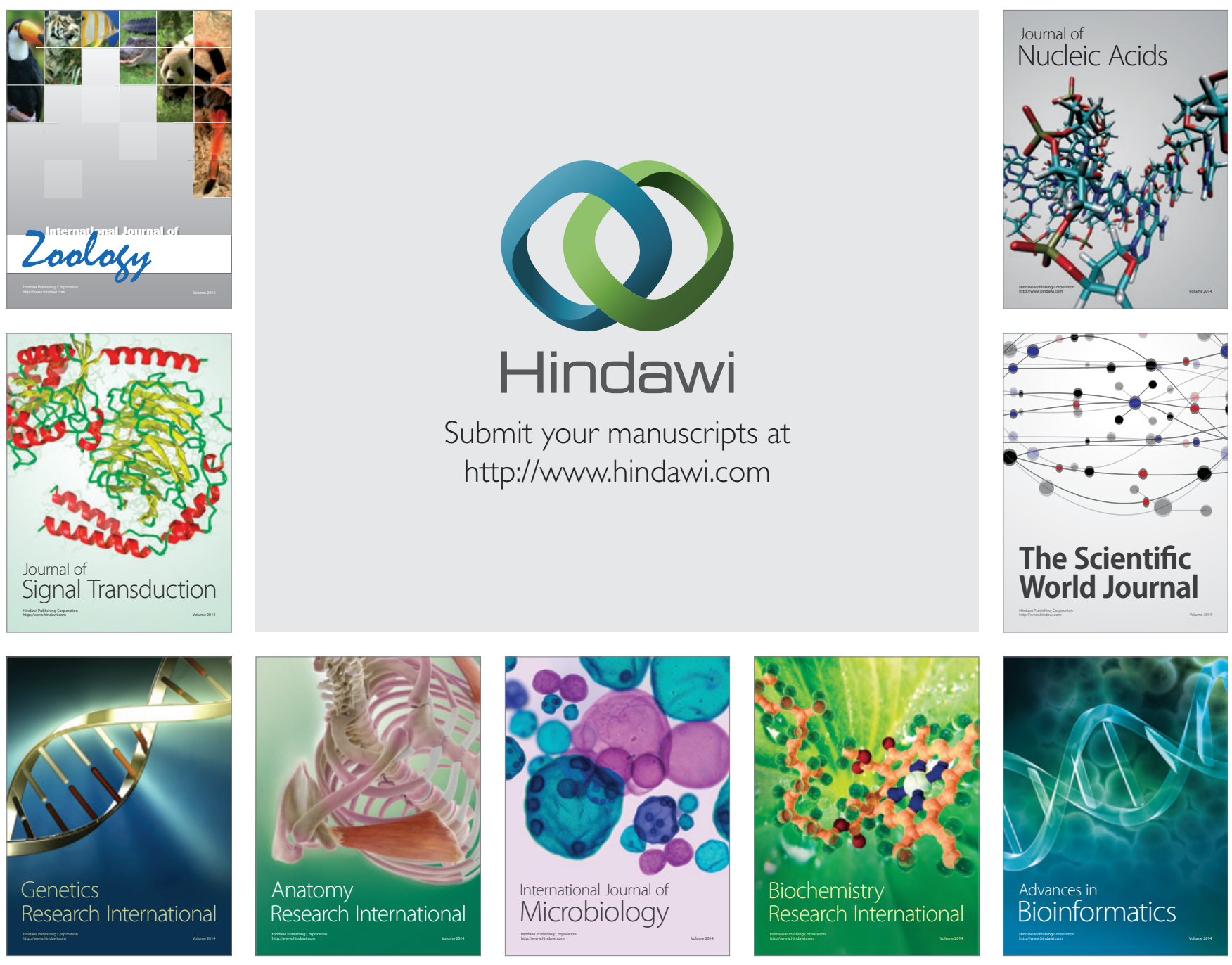

The Scientific World Journal
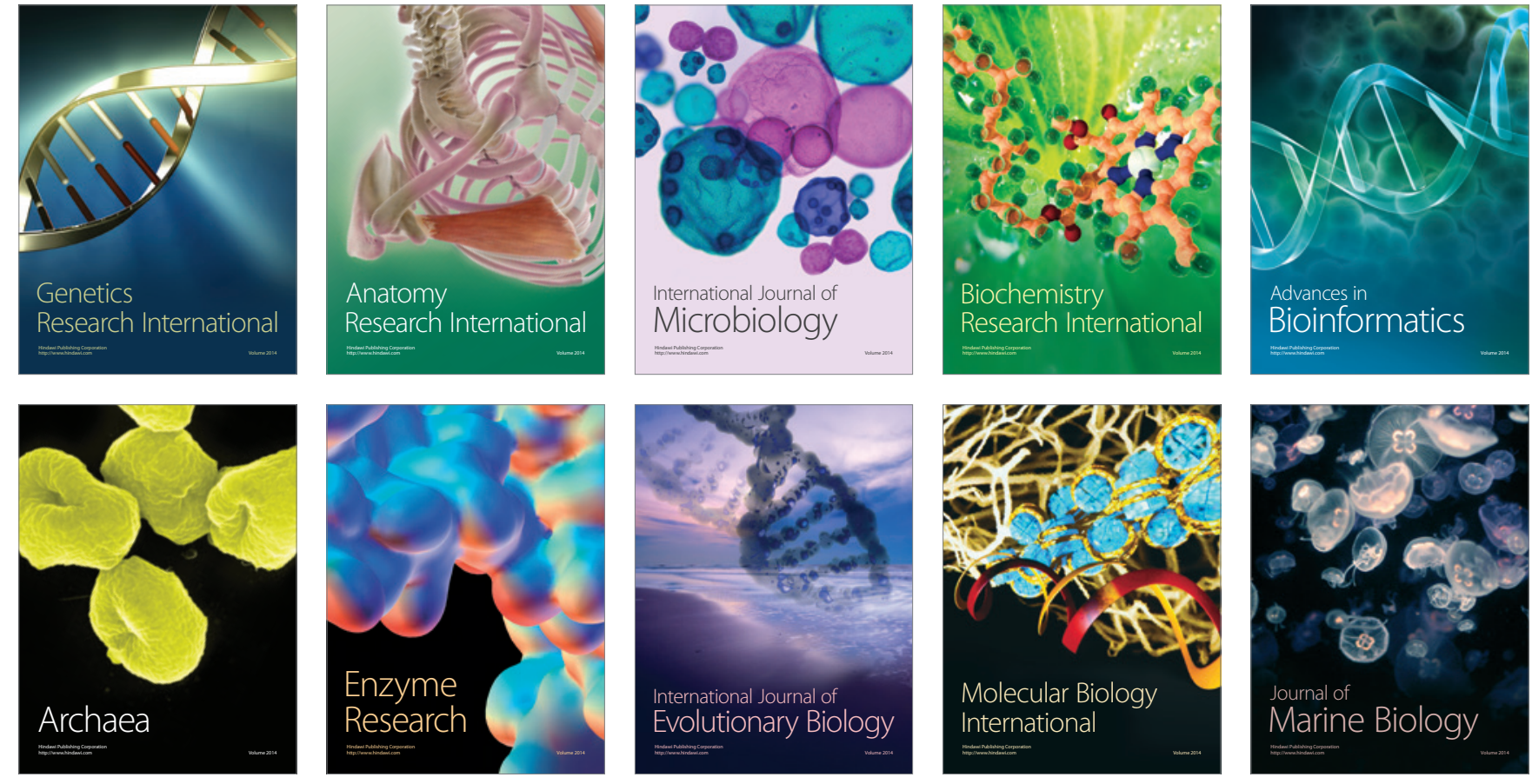